\title{
Projectar uma década - que coordenadas para o futuro da medicina geral e familiar?
}

Maria José Ribas*

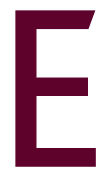

CONFERÊNCIA DE ENCERRAMENTO DO

27. ${ }^{\circ}$ ENCONTRO NACIONAL DE CLÍNICA GERAL VILAMOURA, 20 DE MARÇO DE 2010

sta conferência não é uma revisão baseada na evidência, mas sim em reflexões, sentimentos, desejos e pensamentos meus e de muitos colegas médicos e não médicos que tiveram a generosidade de dividir comigo as suas opiniões e sonhos. Esta reflexão pretende responder a um repto da direcção da Associação Portuguesa de Médicos de Clínica Geral: projectar uma década - que coordenadas para o futuro da medicina geral e familiar?

Estes são tempos de incerteza para muitos de nós.

- Temos um futuro ou somos um anacronismo indesejado?

Alguns médicos expressam dúvidas sobre o seu futuro, outros apressam-se a reformar-se, usando os mecanismos que o Estado lhes oferece, e muitos passam hoje por tempos de angústia gerados pela mudança.

Alguns, ainda, sentem que não sabem bem qual é o seu papel, o seu perfil e que fazem, diariamente, tarefas que já não reconhecem como suas. Outros imaginam e temem perdas, para outras profissões da saúde, do protagonismo a que se habituaram há muito. E muitos seguem a mudança sem medo e são apelidados de entusiastas acríticos. Ou, como lhes chamava o Prof. Walter Oswald, na abertura deste Encontro, optimistas e tolos.

O medo de modificações contratuais, avaliações, medições, contratualizações, comparações e auditorias assola-nos os sonhos, transformando-os em pesadelos nocturnos e diurnos.

A acessibilidade parece contradizer a continuidade, e a falta de tempo luta com o holístico.

Por isso, é preciso saber quem somos e encontrar uma forma simples e clara de explicar qual o nosso papel, a nós mesmos e aos outros.

*Médica de Família - ACES Porto Ocidental
Esta reflexão centra-se em três questões:

- Como queremos que seja o nosso médico de família no futuro?

- Em que contexto iremos trabalhar?

- Que desafios e mudanças serão necessários na próxima década e provavelmente nas seguintes?

Tentando responder à primeira questão desta conferência, perguntei a algumas pessoas: «-Como gostarias que fosse o teu médico de família?»

Comecei lá por casa. Uma pequena sábia de 7 anos, a minha filha, respondeu-me:

«Por acaso, a minha mãe é médica...Mas se não fosse, gostava que (o médico) fosse simpático, querido, cuidadoso, engraçado tal e qual a minha mãe. Também me parece que toda a gente gosta disso. Quando me tratasse não ia ter medo nem dor e se calhar também ele ia ficar orgulhoso e feliz."

E eis o que responderam os colegas, na primeira pessoa:

«Deixa-me dizer-te o que espero do meu médico de família.

Irá ser delicado, atencioso, humano e culto.

Cortês, simpático e natural nos seus afectos, sem ser meu amigo do peito nem meu pai.

Irá gostar de pessoas, (mesmo os feios, porcos e maus).

Provavelmente isso será mais fácil se for ele próprio uma pessoa.

Deve saber ouvir e mostrar genuíno interesse por mim, prestar atenção ao que eu digo e centrar-se apenas em mim quando eu o procuro.

Deve ser flexível e até adoptar outros pontos de vista: só assim poderá compreender-me, aceitar e respeitar as minhas decisões. Repito: quero que me ouça e me perceba, sem juizos de valor. E quero que nas suas respostas seja assertivo.

Quero que me transmita serenidade, quando o procuro aflito, curiosidade, quando lhe quero falar, e humildade para saber dizer «não sei». 
É seguro, sensato e prudente nas suas decisões. Só assim terei a certeza que não sou objecto do seu empirismo.

É uma pessoa digna, honesta, bem formada. É uma pessoa em quem eu posso confiar.

Está disponivel, mas deixa-me escolher a forma como o procuro. Nem sempre preciso de estar com ele, às vezes basta-me poder telefonar ou escrever-lhe. Mas ele «está lá».

Quando nos encontramos, gosto que me chame na sala de espera pelo meu nome e me acolha com um sorriso nos lábios.

E gosto que se despeça de pé no final. Fui educado à moda antiga.

Quero que me olhe nos olhos quando está comigo.

Confesso que me aborreço um bocado quando quero explicar-lhe um ponto de vista e ele está a teclar no computador e a olhar para o ecrã, como que absorto; mas normalmente reparo que nesses momentos de aparente alheamento, ouviu mesmo o que eu dizia e dá-me a entender que não se perdeu.

Gosto que esteja bem-disposto, sem que no entanto brinque com o que sinto. Aprecio o seu sentido de humor. Às vezes noto que se irrita (se calhar sou eu que o irrito...) mas isso não transparece na nossa relação.

Gosto que tenha tempo para conversar comigo, mesmo quando o tempo do relógio não é igual ao tempo da nossa consulta. Quero que seja o meu médico.

Deve respeitar-me em vez de me tratar como uma máquina que precisa de conserto.

Gosto que mostre compaixão, sem me diminuir. Eque transborde de empatia positiva.

Quero que seja culto e se interesse por outras coisas além da medicina, como a arte, a literatura ou a política. Por vezes sabe-me bem começar a nossa consulta por outro tema que não o que me aflige.

Quero que seja saudável e fisicamente capaz de ainda me atender ao fim de um dia de trabalho.

O meu médico de família coloca a relação acima da evidência e a ética acima de tudo.

Écompetente, diligente e trabalhador. É honesto e sensato. Quando não sabe o que fazer diz-mo com sinceridade e pede ajuda a outros colegas.

Não me importo nada quando lhe conto coisas que me estão a acontecer e ele tem necessidade de consultar programas que tem no computador para ajuizar me- lhor o que se está a passar comigo. A seguir, aproveita para me mostrar gráficos e figuras para eu entender melhor o que me diz.

É humilde, questiona-se a si mesmo e procura permanentemente a verdade científica. Écurioso e sedento.

Tem uma sólida formação médico-científica de base, e sobretudo tem o cuidado, auto-disciplina e método adequados para se manter actualizado. Gosto que esteja preocupado em saber mais.

É organizado, eficiente, dedicado e pontual.

Como técnico quero que seja o melhor, mas sobretudo que me explique e partilhe comigo as suas decisões. Quero que seja um bom comunicador e um bom ouvinte. Quero que identifique os meus medos, mesmo quando eu próprio não os conheço ou não lhos confesso por acanhamento.

Compreende que uma consulta hoje pode ter um enorme impacto dez consultas depois e faz-me compreender a continuidade de cuidados.

Gosto que se mostre seguro.

Gosto que seja acessivel e esteja disponível para me atender, mesmo que de forma indirecta. Far-me-á compreender que a acessibilidade é muito mais do que marcar consultas quando se deseja.

Explica-me que tem autonomia para me receitar o que quiser, e que ele e os colegas seguem regras científicas que adoptam em conjunto para haver mais probabilidades de estarem a tomar as decisões correctas. Quando me receita algo explica-me sempre os prós e os contras dessa medicação e o que se espera com a mesma, $e$ no fim negoceia comigo.

Tem métodos de trabalho e ferramentas únicos, que lhe permitem trabalhar lado a lado comigo, o doente.

E acaba sempre com uma pergunta interessada sobre os meus filhos...

É o gestor da minha saúde. Como tal é valioso, mas não é caro; é generoso, mas não é esbanjador. Utiliza os recursos de forma racional. Os seus interesses são os meus. Nesse sentido, não é só meu médico, mas é também meu advogado.

Se não confiar nele, tenho de o trocar...

Ficarei contente e até orgulhoso se souber que o meu médico é também um investigador ou um professor, desde que isso não prejudique a nossa relação e não o faça ausentar-se muito. Como doente só me interessa que investigue enquanto esse trabalho reverter a meu favor. 
Não gostaria que estivesse sempre a fazer perguntas, portanto terá de ser um investigador subtil.

Se investigar, deverá ser rigoroso, eticamente irrepreensivel e humanamente sensivel. Mas nem todos podem, querem ou precisam de ser investigadores. Não me importo que o meu médico não goste de fazer investigação desde que saiba onde e como procurar a informação necessária e a saiba interpretar criticamente.

Quererei que pratique medicina de acordo com a melhor evidência científica existente. Por isso, deve saber ler e, se possivel, pertencer a uma rede de partilha de boas práticas.

Se te parece que estamos a falar de médicos de família que já conheces, extraordinário!"

\section{Porque para curar uma pessoa temos primeiro de ser pessoas (Abraham Heshel).}

-E em que contexto irá trabalhar? -Como deverá ser o centro de saúde? - perguntei novamente.

A minha filha escreveu: «Limpo. Num centro de saúde, que é para tratar pessoas, se estiver sujo elas ficam doentes!»

E os colegas, novamente na primeira pessoa:

«O meu médico irá trabalhar num local organizado, com orientações claras e inteligíveis para mim. Terá de ter um bom acesso telefónico e por e-mail.

Quando chego posso estacionar com facilidade. Se possivel, esse local será próximo da minha casa, por isso vou a pé.

Será um espaço moderno, luminoso, arejado, de cores claras e limpo.

As cadeiras vão ser confortáveis e posso ler enquanto espero, sem muitas pessoas à minha volta.

Não haverá muito ruído. Não haverá gritos. Será um lugar tranquilo, embora não me importe que tenha música.

Enquanto espero não tenho nem frio nem calor.

Será um espaço que me transmite confiança no tipo de medicina que lá se pratica. Vai parecer uma clínica privada, embora eu prefira que seja pública.

Idealmente não vou ter de ir a mais lado nenhum porque posso fazer todos os meus exames básicos no próprio local.

Quando lá vou não perco tempo; apenas o necessário para ver o meu problema resolvido e não ter de voltar muitas vezes. Sou sempre atendido à hora marcada.

Os profissionais serão corteses e nunca me farão sentir que, por algum motivo, não deveria estar ali. Pelo contrário, fazem-me sentir que eu sou a razão de eles estaremali. Dão-me as informações que preciso sem mefazer sentir ignorante ou chato. Ou que me estão a fazer um favor...

Os consultórios serão confortáveis, mas simples e convidativos. Talvez com um quadro ou uma fotografia pessoal...

O meu médico trabalha numa equipa saudável em que ele é mais um de outros. Se possível uma equipa que também tenha psicólogos, nutricionistas, podologistas, assistentes sociais e outros profissionais que se complementem. Todos têm os conhecimentos, a autonomia e o equipamento essenciais à prestação de cuidados e todos partilham as decisões e a tarefa de cuidar da sua população comum. E todos estão encantados por trabalhar juntos. Todos usam tecnologias modernas de informação que lhes e me facilitam a vida, em vez de complicá-la. E esta equipa está integrada numa rede de muitas outras, que partilham formas melhores de se organizarem.

Lá dentro respira-se trabalho de equipa e vê-se que todos são responsáveis pelos meus cuidados, mantendo a confidencialidade e o sigilo profissional. Têm um sistema de promoção da saúde bem organizado mas também não quero que me persigam com serviços de que não vejo necessidade.

Quando o meu médico está de férias vou na mesma lá, porque os restantes sabem quem sou e como ajudar- me e são tão simpáticos como ele.

Esta unidade de saúde será um centro de cultura científica, de desenvolvimento técnico e de produção de conhecimento. Será um local de ensino e de aprendizagem por excelência, promotor de investigação, mas ao mesmo tempo um local próximo da comunidade, acessível.»

E que desafios se nos colocam nesta década que começa? - a minha reflexão:

É essencial que o médico de família do futuro ofereça cuidados de alta qualidade a todos os cidadãos, em qualquer lugar, da mesma forma, sem perder os seus atributos de ouvir, centrar-se no doente, cuidar e ter a sua confiança.

A coordenação e a personalização da maioria dos 
cuidados deverão continuar a residir junto do médico de família, que conhece e entende o indivíduo, o seu ambiente, a sua família, o seu trabalho, a sua personalidade.

A confiança pública nos médicos de família é elevada e tem de ser fundamentada em práticas clínicas de alta qualidade, centradas na pessoa.

A Reforma dos Cuidados de Saúde Primários tem absolutamente de preservar esta relação de confiança entre os doentes e os seus médicos.

Para além da clarificação do nosso perfil junto da população e da definição do contexto de trabalho, temos e teremos vários desafios que resumo em alguns pontos e que incluem, não necessariamente por esta ordem:

1..$^{\circ}$ - A melhoria do acesso aos cuidados de saúde para todos, com equidade e qualidade, prestando cuidados de excelência de forma igual, a qualquer cidadão, independentemente do local ou tipo de unidade de saúde. Este acesso deve ser mais flexível e centrado no indivíduo, que exige respostas mais rápidas, sem, no entanto, perder a continuidade necessária que vai para além dos contactos directos: continuidade da informação, continuidade da equipa, continuidade das regras de actuação. Assim, o trabalho em equipa, independentemente do médico pessoal, torna o doente, um doente da equipa; $2 .^{\circ}$ - A capacitação de médicos e utentes, em particular na gestão da doença crónica, com o fim do paternalismo e da imposição do parecer do médico. Desejam-se pessoas mais competentes para cuidar e tomar decisões sobre a sua saúde, envolvidas nas decisões acerca de si, eventualmente com acesso à sua área pessoal de informação clínica e conscientes de que todos contribuímos para a sustentabilidade do sistema;

$3 .^{\circ}$ - A oferta de cuidados de saúde na própria comunidade e ambiente do doente, com integração das vertentes de saúde pública, da enfermagem da comunidade e de outras profissões no planeamento estratégico e execução dos mesmos. Para tal, nós, médicos, teremos de cooperar com equipas alargadas de profissionais que, no conjunto, formam um todo, com o objectivo comum: o de prestar melhores cuidados a uma população comum;

$4 .^{\circ}$-A coordenação geral dos cuidados dentro do sis- tema de saúde, incluindo a gestão da interface com outros níveis de cuidados e a gestão dos doentes que não têm critérios para estar em mais lado nenhum, com alta dos hospitais, sem indicação para operar, sem indicação para internar, sem dinheiro para pagar, sem família para os acolher, numa óptica de advocacia do doente, com especial ênfase no desenvolvimento de processos de prevenção do erro e de melhoria da segurança do doente;

$5 .^{\circ}-\mathrm{O}$ investimento de tempo e esforço na gestão individual de cuidados aos doentes com multi-morbilidade, em particular idosos e doentes terminais, com partilha e transferência de responsabilidades e de competências para uma equipa alargada de profissionais dos cuidados de saúde primários;

$6 .^{\circ}-\mathrm{O}$ crescimento em mancha do modelo organizativo, em tudo semelhante às USF, não obrigatoriamente com esse nome, mas com equipas multidisciplinares, a trabalhar em locais dignos e que dignificam a nossa especialidade (e não espaços em que não é possível que a população acredite no elevado nível de qualidade da medicina que ali se pratica). Equipas autónomas, co-responsabilizadoras e com gestão partilhada, que se comprometem a prestar cuidados de elevada qualidade numa lógica de contratualização clara e bidireccional com objectivos fáceis de monitorizar, baseados na evidência e centrados em boas práticas;

7. ${ }^{\circ}$-O desenvolvimento, aperfeiçoamento e adopção de sistemas de informação eficientes e amigáveis para os utilizadores, com novas funcionalidades de ajuda na decisão clínica e na redução do erro, orientados para a prestação de cuidados;

8. ${ }^{\circ}$ - O desenvolvimento da disciplina académica, com o reforço dos departamentos nas Universidades, visando uma aumento da influência e impacto do ensino da medicina geral e familiar, em estádios cada vez mais precoces da formação dos alunos de Medicina;

$9 .^{\circ}-\mathrm{O}$ desenvolvimento em qualidade e quantidade de estudos de investigação feitos por nós, na comunidade, que produzam conhecimentos úteis para a nossa prática diária, apostando em redes ou comunidades de práticas, e envolvendo todos os intervenientes no terreno: faculdades, internatos, orientadores e internos, médicos e equipas; Estudos já exis- 
tentes deverão ser publicados para que o conhecimento se generalize;

$100^{\circ}$ - O desenvolvimento e aperfeiçoamento desta oportunidade que é o novo programa de internato, que permitirá formar cerca de 3000 novos médicos de família nos próximos dez anos. Numa renovação sem precedentes, estes novos especialistas constituirão metade dos médicos de família necessários ao SNS. Para tal é preciso que «vistam a camisola», mas também que sejam respeitados como profissionais. Que possam escolher o seu local de trabalho com base em critérios de mérito; que possam sentir que o tempo e energia que despenderam na sua formação poderá ser empregue naquilo para que se prepararam; que possam sentir que vale a pena trabalhar no SNS;

$11 .^{\circ}$ - O desenvolvimento de um processo de formação contínua credível, independente e isenta, associada a um sistema de auto-avaliação e creditação que permita valorizar os profissionais que mantêm um elevado nível de actualização e desempenho; $12 .^{\circ}$ - A consolidação da governação clínica como garante da melhoria das boas práticas e da melhoria contínua da qualidade;

13. ${ }^{\circ}$ - Os avanços tecnológicos, que potenciem diagnósticos e procedimentos minimamente invasivos perto dos doentes e que venham a ter um maior peso nas características do futuro médico de família. Estas técnicas são hoje residuais e dependentes da vontade individual.

Quanto mais o mundo se complica, mais nós, médicos de família, seremos necessários.

Estamos na sala de estar de um sistema de saúde fervilhante de mudança, inseridos em equipas multidisciplinares e manteremos o importante papel de advogados dos nossos doentes.

Temos um conjunto único de competências e de habilidades para lidar com o risco e a incerteza e somos o centro e a fonte da efectividade e da eficiência do SNS.

Estas capacidades únicas, centradas na pessoa, tomarão uma importância crescente numa sociedade progressivamente mais técnica e despersonalizada.

Nós somos essenciais ao sistema e sem nós o sistema colapsa, não funciona.

Na década que se inicia, a medicina familiar poderá e deverá ser baseada na evidência, mas continuará, sem dúvida, a ser baseada na relação e na pessoa.

Os doentes confiam mais que nunca nos seus médicos. Por isso, os Cuidados de Saúde Primários têm de consolidar-se como a rocha de apoio do SNS em Portugal, pela sua importância e pelo volume de profissionais, utentes e trabalho que representam.

Acredito profundamente que os Médicos de Família têm um papel vital, não nesta década que se inicia, mas já hoje e muito para além dela. Já assim acreditava quando optei pela minha especialidade e já assim acreditava quem fundou a APMCG.

A próxima década será feita por cada um de nós e pelas nossas equipas e será moldada na forma que lhe quisermos dar. Cada um com as suas características, a sua personalidade, as suas capacidades, a sua experiência, os seus dramas e as suas alegrias.

Nem todos seremos investigadores, nem todos seremos professores, nem todos gostaremos de informática. Mas o que fizermos, faremos bem. Todos temos esta capacidade única de nos relacionarmos e gostarmos de pessoas. Essa riqueza que nos caracteriza é também o que nos torna únicos como médicos... assim provemos a nossa eficiência e efectividade. Assim saibamos nós trazer sempre uma solução agarrada a um problema. Assim tenhamos nós decisores que acreditam connosco.

Sozinhos não fazemos nada, não somos nada. Mas juntos podemos fazer a mudança e ir até onde a nossa imaginação nos levar.

A próxima década - o futuro - é o que nós quisermos que seja. Sejamos insensatos, ousados, imaginativos e arrojados e tornaremos os anos que nos restam de trabalho, sejam eles 2,10 ou 30, naqueles que nos permitirão no fim dizer que fizemos a diferença.

Alguns dos desafios que levantamos aqui não podem esperar, porque o futuro é hoje.

Bernard Shaw dizia: «O futuro pertence aos insensatos, os que olham para a frente e não para trás, estão certos apenas da incerteza e tem a capacidade e a confiança de pensar completamente diferente.»

A APMCG sempre foi exímia a fazer isto. Por isso, devolvo o repto à sua Direcção, para que nos lidere e volte a apontar caminhos que outros ainda não sonharam. 
Mas não o façam sozinhos. Envolvam toda a gente, porque o pensamento constrói-se com as ideias de todos e as revoluções fazem-se com o envolvimento de todos.

Resta-me agradecer a todos os colegas que generosamente partilharam comigo os seus contributos. Ninguém constrói nada sozinho e ninguém inventa nada que já não tenha sido pensado. Alguns têm apenas o privilégio e a honra de poder ouvir e sintetizar o que todos em conjunto pensamos.

O meu agradecimento vai pois para estes colegas:

Vítor Ramos · Ana Ferrão · Luís Pisco · Igor Svab . Graça Azevedo · Jaime Correia De Sousa · André Biscaia - José Augusto Simões · João Sequeira Carlos · Ana Sardinha · Paz Trigueiros · Dilermando Sobral · Luz Loureiro - Joana Melo Cabrita - Fernando Almeida - José Carlos Leitão · Rui Cernadas · Cândida Palmeirão - Luciana Monteiro - Michael Weingarden · Clara
Ferreira · John Yaphe · Jorge Rocha · Conceição Outeirinho · Alcindo Maciel Barbosa · Justin Allen . Judite Neves · José Nunes · Michael Kochen · Emília Peneda $\cdot$ Fergus O Kelley · Armando Brito de Sá · Mário Moura · Tiago Sousa Veloso · Hilton Koppe · André Matalon · Jesus Perez Sanchez • Cristina Galvão · Helena Beça,

e também para os que não baixam os braços, aos que não desistem, aos que resistem, aos que levantam os braços, aos que inventam soluções, aos que acreditam.

Obrigada!

\section{ENDEREÇO PARA CORRESPONDÊNCIA}

Maria José Ribas

E-mail:mariajribas@gmail.com

Recebido em 06/04/2010

Aceite para publicação em 16/04/2010 